\title{
ESTADO DA ARTE E O RUMO DO CONHECIMENTO CIENTÍFICO EM SECRETARIADO EXECUTIVO: MAPEAMENTO E ANÁLISE DE ÁREAS DE PESQUISA
}

STATE OF THE ART AND THE DIRECTION OF SCIENTIFIC KNOWLEDGE IN THE EXECUTIVE SECRETARIAT: MAPPING AND ANALYSIS OF RESEARCH AREAS

\section{Marlete Beatriz Maçaneiro}

Doutora em Administração pela Universidade Federal do Paraná - UFPR

Professora da Universidade Estadual do Centro-Oeste - UNICENTRO

E-mail: marlete.beatriz@yahoo.com.br (Brasil)

\section{Marcos Roberto Kuhl}

Doutor em Administração pela Universidade Federal do Paraná - UFPR Professor da Universidade Estadual do Centro-Oeste - UNICENTRO

E-mail: marcosrobertokuhl@yahoo.com.br (Brasil) 
Estado da arte e o rumo do conhecimento científico em secretariado executivo: mapeamento e análise de áreas de pesquisa

\title{
ESTADO DA ARTE E O RUMO DO CONHECIMENTO CIENTÍFICO EM SECRETARIADO EXECUTIVO: MAPEAMENTO E ANÁLISE DE ÁREAS DE PESQUISA
}

\section{RESUMO}

O objetivo deste estudo é realizar um mapeamento da produção científica dos formados em Secretariado Executivo, no sentido de verificar as áreas e a quantificação pertinentes a essa publicação, bem como analisar a relação entre essa publicação e a titulação dos pesquisados. Este estudo é do tipo exploratório e descritivo, sendo que a metodologia foi ancorada na abordagem quantitativa, por meio da estratégia de levantamento de dados em bases secundárias de acesso público, tais como a Plataforma Lattes e o WebQualis, dentre outras. O tratamento, análise e interpretação das evidências foram realizados através de técnicas estatísticas descritivas. Foram analisados os currículos Lattes de profissionais formados em Secretariado Executivo e que possuíam algum tipo de produção científica, totalizando uma amostra de 219 profissionais, vinculados a instituições/empresas de todas as regiões do Brasil. Dentre os principais resultados, verificamos que apenas 33,7\% da produção estão na área de Secretariado ou fazem relação com ela e que os que possuem somente graduação e especialização publicam em maior número na área, enquanto que os do nível de mestrado e de doutorado publicam bem menos na área de Secretariado. Esse resultado confirma a hipótese do estudo, de que as publicações realizadas por profissionais com nível de mestrado e doutorado são realizadas, em sua maioria, em outras áreas que não no contexto do Secretariado Executivo.

Palavras-chave: Secretariado Executivo; Conhecimento Científico; Produção Bibliográfica.

\section{STATE OF THE ART AND THE DIRECTION OF SCIENTIFIC KNOWLEDGE IN THE EXECUTIVE SECRETARIAT: MAPPING AND ANALYSIS OF RESEARCH AREAS}

\begin{abstract}
The aim of this study is to map the scientific production of graduated in the Executive Secretariat, in order to verify and quantify the areas relating to this publication, as well as analyzing the relationship between this publication and the titration of respondents. This study is exploratory and descriptive, and the methodology was grounded in a quantitative approach, through the strategy of data collection in secondary bases of public access, such as Lattes Platform and WebQualis among others. The analysis and interpretation of the evidence was done by means of descriptive statistical techniques. We analyzed the Lattes curricula of professionals graduated in the Executive Secretariat and what had some kind of scientific production, resulting in a sample of 219 professionals from institutions / companies from all regions of Brazil. Among the main results, we found that only $33.7 \%$ of production are in the area of the Secretariat or make relationship with her and those who have only undergraduate and specialization publish in greater numbers in the area, while the master's level and doctoral publish much less in the area of Secretariat. This result confirms the hypothesis of the study, that the publications made by professionals with master's and doctoral level are held mostly in areas other than in the context of the Executive Secretariat.
\end{abstract}

Keywords: Executive Secretariat; Scientific Knowledge; Bibliographic Production. 


\section{INTRODUÇÃO}

Há um consenso entre os estudiosos de Secretariado Executivo de que a área carece de publicações e pesquisas científicas para se firmar teoricamente (Bíscoli, 2012; Durante, 2010, 2012; Maçaneiro, 2012; Nascimento, 2012; Nonato Júnior, 2008, 2009) e prover o campo com a criação de área de conhecimento específica. No entanto, para Sabino e Marchelli (2009, p. 610), o Secretariado Executivo, como área do conhecimento, está “[...] historicamente a reboque da ciência e se forma no âmbito de uma conjugação social extremamente forjada por relações de gênero [...]”.

A despeito disso, em estudo anterior (Maçaneiro, 2012), levantaram-se hipóteses para a falta de uma identidade científica, as quais se justificam na trajetória da formação profissional dessa área. Uma delas, a terceira, definiu-se como relacionada com a falta de pesquisa científica realizada pelos profissionais mestres e doutores na área específica de Secretariado Executivo.

Essa hipótese partiu da percepção de que, quando os profissionais estão inseridos em mestrado ou doutorado, têm dificuldade para realizar pesquisas na área de Secretariado. Isso porque os cursos stricto sensu priorizam a publicação na área específica de cada um, para as avaliações dos programas de pós-graduação. O profissional dá prioridade para as pesquisas relacionadas às disciplinas e/ou teses e dissertações que está realizando, as quais normalmente não estão relacionadas com os problemas do Secretariado, por não existir cursos stricto sensu nessa área.

Não vemos a publicação científica em outra área como negativa; ao contrário, ela proporciona a oportunidade de melhor qualificação profissional aos formados em Secretariado Executivo. Bíscoli (2012, p. 48) também ressalta esse aspecto como positivo, como agregação de valor científico ao formado em Secretariado.

\footnotetext{
Vale ressaltar que as publicações fora da área de secretariado executivo podem representar um diferencial aos pesquisadores, pois agregam valor ao seu currículo no que se refere à quantidade de publicações quando submetem seus projetos aos editais de fomento. Ou seja, nesse momento parece ser conveniente pesquisar e publicar fora da sua área de atuação na medida em que se consegue a inserção na comunidade científica que neste momento é contemplada pelos órgãos envolvidos. (Bíscoli, 2012, p. 48)
}

Durante (2010, p. 4) ainda salienta que "o pequeno envolvimento de professores e alunos com a pesquisa é elucidado até mesmo pela quantidade de grupos de pesquisa cadastrados no $\mathrm{CNPq}$, que se resumem a quatro, de acordo com a pesquisa realizada em setembro de 2010 no site deste conselho." Portanto, esse é outro dado importante que mostra a falta de envolvimento dos professores/profissionais com a pesquisa em Secretariado, uma vez que os grupos de pesquisa se

Revista de Gestão e Secretariado - GeSec, São Paulo, v. 4, n. 3, p 157-188, dez. 2013. 
Estado da arte e o rumo do conhecimento científico em secretariado executivo: mapeamento e análise de áreas de pesquisa

caracterizam no eixo condutor das demandas das áreas científicas. Além disso, Nascimento (2012, p. 112) também ressalta que "em que pese algumas iniciativas por parte de alguns pesquisadores ou instituições, as investigações na área ainda ocorrem de maneira muito particular e desarticulada”.

Isso acarreta na hipótese deste estudo de que há um pequeno número de publicações realizadas por profissionais com nível de mestrado e doutorado, na área específica do Secretariado. Ressaltamos que essas publicações, oriundas de profissionais com esses títulos, supostamente surtiriam em melhores trabalhos, tendo em vista a experiência na produção do conhecimento científico realizada pelos mestres e doutores. Portanto, o objetivo deste estudo é realizar um mapeamento da produção científica dos formados em Secretariado Executivo, no sentido de verificar as áreas e a quantificação pertinentes a essa publicação, bem como analisar a relação entre essa publicação e a titulação dos pesquisados.

Os resultados poderão contribuir para o aprimoramento dos estudos de pesquisa dos profissionais inseridos não só na área de Secretariado Executivo, mas também de outras áreas envolvidas com este contexto. Nesse sentido, ressaltamos que o resultado deste estudo não deverá ser tomado como algo prescritivo ou normativo, mas, sim, como um trabalho reflexivo, sugestivo de direcionamento na condução de pesquisas, tanto de professores, como de profissionais e de acadêmicos ainda em formação. É nesse contexto que este estudo está amparado: ele pretende buscar subsídios que tragam à tona essa problemática e promover reflexões que possam nos auxiliar em um caminho a desvendar e a mudar esse direcionamento da pesquisa científica.

O trabalho segue com o referencial teórico, trazendo uma breve discussão em torno da importância da pesquisa científica para a formação das áreas de conhecimento. Em seguida, apresentamos a metodologia do estudo e os resultados da pesquisa de dados secundários, seguidos das considerações finais com os principais resultados e as perspectivas futuras em termos de indicação da consolidação da cientificidade da área de Secretariado.

\section{REFERENCIAL TEÓRICO}

Na sua concepção, a pesquisa científica é a atividade básica da ciência na indagação e construção da realidade. Podemos defini-la como ações de investigação planejada, que utiliza métodos e técnicas em busca de soluções para problemas propostos (Minayo, Deslandes, \& Gomes, 2007; Rodrigues, 2006). Segundo Salomon (2000, p. 4), a atitude crítica “[...] se exige de todo aquele que se propõe atingir o conhecimento científico. [...] É preciso começar sempre pelo

Revista de Gestão e Secretariado - GeSec, São Paulo, v. 4, n. 3, p 157-188, dez. 2013. 
exame crítico para negar o que é dado, dito, posto, aceito como absoluto, eterno, imutável, definitivo." Ou seja, a pesquisa deve compor um processo de formação científica, em que o pesquisador dialoga criticamente com a realidade que o cerca.

É importante aqui destacar a concepção de Demo (2006) sobre a necessidade da desmistificação da pesquisa. O autor afirma que isso é necessário “[...] para não encerrá-la em sofisticações operáveis apenas por castas superiores e raras. [...] pode-se tentar cotidianizar a pesquisa, como processo normal de formação histórica das pessoas e grupos, à medida que significar também condição de domínio da realidade que nos circunda”. (Demo, 2006, p. 9). Com isso, poderíamos pensar a pesquisa não como um mérito apenas de pessoas com formação stricto sensu, mas que possa ser desenvolvida como processo de formação, desde as bases acadêmicas.

No entanto, não se deve deixar de lado o rigor necessário nas técnicas para a efetivação de uma pesquisa científica séria. Bachelard (2001, p. 33) alerta que "as regiões do saber científico são determinadas pela reflexão." Ou seja, o trabalho científico exige do homem reflexão, capacidade de expor suas ideias e habilidade para compor seus projetos vinculados ao cotidiano profissional (Matias-Pereira, 2007). De acordo com Burrel e Morgan (1979, p. 5), “Todos os cientistas sociais abordam seus temas por meio de pressupostos implícitos ou explícitos a cerca da natureza do mundo social e da maneira como eles podem ser investigados." Isso nos leva a crer que o fazer da pesquisa científica não é um processo fácil, mas também não pode ser considerado algo a ser alcançado por poucos. Contudo, Salomon (2000, p. 121) ressalta que “[...] muitos estudantes universitários e profissionais de nível superior não tem feito da pesquisa atividade de seu ofício ou dela se afastam, por considerá-la inacessível [...]".

A partir dessas considerações, entendemos que o processo de pesquisa se desenvolve ao longo da carreira acadêmica do sujeito, em que os passos iniciais deveriam ser dados ainda no ensino fundamental e, principalmente, no ensino médio. Aqui é importante o alerta de Demo (2006, p. 10), quando menciona que "predomina entre nós a atitude do imitador, que copia, reproduz e faz prova. Deveria impor-se a atitude de aprender pela elaboração própria, substituindo a curiosidade de escutar pela de produzir." Consideramos que - na cultura a qual tudo aquilo que é reproduzido e copiado é chamado de "pesquisa" - não há como entender o processo de pesquisa científica como algo proveniente de uma apreensão crítica da realidade. De acordo com Salomon (2000), o processo de pesquisa é definido como um pensar reflexivo, algo que deve ser visto dinamicamente, progressivo-regressivo e contínuo-descontínuo. Nesse sentido, Pádua (1997, p. 31) já mencionava que "no plano da pesquisa, epistemologia, método e procedimentos técnicos se constituem como elementos indissociáveis em todo o processo de investigação que se desencadeia com o

Revista de Gestão e Secretariado - GeSec, São Paulo, v. 4, n. 3, p 157-188, dez. 2013. 
pesquisar: entretanto este processo está longe de ser homogêneo, linear, uniforme, a-histórico.” Ao contrário, esse processo é histórico e contraditório, na medida em que não é contínuo em seu desenvolvimento, possui movimentos de ir e vir no contexto de sua realização, mas, sobretudo, é um fazer reflexivo.

Em sua expressão mais singela, a pesquisa supõe um mínimo de capacidade e o máximo de esforço. Em sua mais alta significação, além de capacidade e esforço, a imaginação criadora. Mas, em todos os seus níveis, supõe sempre método, reflexão analítica e crítica, tanto em relação ao objeto que está sendo pesquisado como em relação aos métodos postos em prática no descobrimento e na prova dos resultados. (Salomon, 2000, p. 150)

Portanto, essa concepção de pesquisa séria, circundada por procedimentos próprios e que garantam a sua validade e confiabilidade, deveria ser incutida nos sujeitos desde o início de sua formação científica. Entretanto, o que se observa na maioria dos acadêmicos que ingressam do ensino superior é uma formação científica ainda marcada pela "atitude do imitador", e é somente nessa etapa acadêmica que podemos considerar o início do processo de formação científica.

Sendo assim, a realidade nos faz considerar que o amadurecimento dessa formação científica somente ocorre no nível stricto sensu, em que o sujeito já possui, em tese, uma bagagem de pesquisa que o coloca em um patamar de produção científica mais qualificada. De acordo com Demo (2006, p. 63), “a pós-graduação faz desafio específico à criatividade de elaboração própria, sobretudo no doutorado".

Nesse sentido, as deficiências em pesquisa no nível de graduação da área de Secretariado Executivo são evidentes, já que, em sua maioria, o acadêmico já se encontra inserido no mercado de trabalho, quando ainda está em formação. Por isso, poucos são os alunos que se interessam pela produção de pesquisa científica ou que participam de programas institucionais de iniciação científica, monitoria, dentre outros relacionados ao campo acadêmico.

Pereira, Moreira e Baeta (2012, p. 141) realizaram estudo com o objetivo de

[...] investigar os fatores motivacionais para a pesquisa científica dos discentes do curso de Secretariado Executivo em nove IFES brasileiras [...] pretendeu-se, também, analisar quais os fatores determinantes para a lacuna de produção científica na área aqui estudada. Em seguida almejou-se verificar as possíveis razões para a falta de interesse em pesquisa por parte dos estudantes de Secretariado Executivo [...]

A pesquisa foi realizada por meio de levantamento realizado com 268 estudantes dessas Instituições Federais de Ensino Superior (IFES), com análise estatística através da análise fatorial, de cluster e do teste de Alpha de Crombach. Os resultados da pesquisa indicaram que os alunos 
não são motivados à pesquisa científica, e sim têm maior preocupação com a prática profissional, por meio de estágios. Foram identificados quatro fatores principais de motivação para a pesquisa, em ordem de importância: 1) a influência da universidade; 2) estágio e aperfeiçoamento; 3) interesse pessoal; e 4) disciplinas de graduação. No entanto, tais fatores foram mais considerados para a formação profissional desses acadêmicos do que para a pesquisa propriamente dita. (Pereira, Moreira \& Baeta, 2012)

A justificativa para isso pode estar no fato de que as grades curriculares dos cursos de Secretariado são compostas, basicamente, por conteúdos específicos da prática profissional (técnicas secretariais), além dos conteúdos de diferentes áreas do conhecimento (Administração, Letras, Economia, Contabilidade, Direito, Ciência da Computação, dentre outras) e algum conteúdo de caráter humanístico (das áreas de Filosofia, Sociologia, Psicologia etc.). Somente uma pequena parte do conteúdo é reservada a temas relacionados à pesquisa científica, sendo que, na maioria dos cursos, há somente uma disciplina denominada de "metodologia científica" ou algo parecido. Ou seja, a grande maioria dos cursos de graduação em Secretariado Executivo trata a pesquisa científica em apenas uma disciplina, relacionada com a metodologia dos trabalhos acadêmicos.

Como destacado por Hoeller (2006), o Secretariado é um curso voltado para as demandas práticas das organizações, mas Nonato Júnior (2009) ressalta, com muita propriedade, que nem por isso deveria deixar de possuir uma epistemologia e teoria do conhecimento necessárias tanto à realização dessas práticas, quanto às suas reflexões teóricas. Bíscoli (2012, p. 38) também destaca que “[...] a profissão evoluiu no sentido prático, acompanhando a evolução do mundo dos negócios. No entanto, é perceptível a necessidade de evolução teórica e conceitual na área de secretariado executivo, o que poderá se concretizar a partir da pesquisa científica bem estruturada".

Então, os cursos de Secretariado precisam também fortalecer a pesquisa em suas grades curriculares, a fim de possibilitar a ampliação e aprofundamento do corpo de conhecimento científico desta área. Isso porque é de consenso que a área precisa se envolver em um processo de formação crítica e emancipatória de espaço científico próprio, o qual está em construção, mas que depende do engajamento de todos. Nonato Júnior (2009, p. 13) aponta “[...] para a necessidade de instaurar uma teorização para o conhecimento secretarial que é praticado no meio acadêmico, despertando nesta área sua identidade intelectual."

Essa identidade científica a ser aprimorada, ou melhor dizendo, construída na área de Secretariado Executivo perpassa por um longo “caminho das pedras". Bachelard (1996, p. 24), destaca que

Revista de Gestão e Secretariado - GeSec, São Paulo, v. 4, n. 3, p 157-188, dez. 2013. 
[...] toda cultura científica deve começar [...] por uma catarse intelectual e afetiva. Resta, então, a tarefa mais difícil: colocar a cultura científica em estado de mobilização permanente, substituir o saber fechado e estático por um conhecimento aberto e dinâmico, dialetizar todas as variáveis experimentais, oferecer enfim à razão razões para evoluir.

Nesse sentido, podemos considerar que a área de Secretariado está iniciando esse processo de catarse e mobilização para a criação de um corpo de conhecimento científico. Observamos uma mobilização da categoria em busca de um espaço científico respeitado e, para isso, eventos científicos estão sendo criados, ampliados e aprofundados em qualidade de pesquisa; periódicos científicos estão sendo criados e melhor qualificados; há maior número de formados em stricto sensu; e também vimos a recente criação da Sociedade Brasileira de Secretariado (SBSEC), que tem por finalidade o desenvolvimento da pesquisa científica na área; dentre outras frentes de mobilização. Mas, ainda deverá construir seus horizontes intelectuais em busca de uma formação epistemológica mais densa, com um caminho reflexivo e crítico do seu papel intelectual e da sua prática nas organizações.

Segundo Demo (2006), a pesquisa científica possui múltiplos horizontes possíveis, tais como os trabalhos construídos em torno de processos empíricos, aqueles que tratam das preocupações teóricas, metodológicas e também no contexto da prática organizacional. Entendemos que, no campo de Secretariado Executivo, a pesquisa científica pode ter os objetivos de: gerar conhecimentos teóricos e práticos sobre a assessoria organizacional; aumentar a eficiência e a eficácia de organizações; melhorar a qualidade de vida no trabalho; auxiliar na produção de produtos e serviços com maior valor agregado para a empresa e consumidores; promover o desenvolvimento social.

A discussão em relação ao objeto do conhecimento secretarial gira em torno do debate, por um lado na definição realizada por Nonato Júnior (2008, 2009, 2012), tendo denominado esse objeto de "assessoria". Por outro lado, Nascimento (2012) considera que esse objeto precisa ser aprofundado, permeado por reflexões teóricas, epistemológicas, históricas e relacionadas à sua práxis. Ou ainda Sabino e Marchelli (2009) que acreditam numa fundamentação teórica arraigada em várias ciências - o que delimita um objeto de estudo interdisciplinar, com aplicação das teorias organizacionais, não se constituindo uma construção teórica autônoma.

Martins, Genghini, Maccari e Genghini (2012) apresentam alguns parâmetros para a definição de linhas de pesquisa, salientando que é necessária a criação de linhas sólidas, que fomentem e retratem a pesquisa oriunda da academia. Somente assim, com o reconhecimento e aprofundamento dessas linhas, será possível o estabelecimento de programas de mestrado na área de

Revista de Gestão e Secretariado - GeSec, São Paulo, v. 4, n. 3, p 157-188, dez. 2013. 
Secretariado.

Ainda que esses temas de pesquisa estejam em discussão e formação, Nonato Júnior (2009, pp. 191-192) define em seu estudo uma classificação categorizada por áreas em que a produção do conhecimento no Secretariado se concentra nos seguintes agrupamentos:

a) teorias profissionais - técnicas do trabalho secretarial; tecnologia secretarial; documentação, correspondência e registro; arquivística, classificação e catalogação; organização e métodos secretariais; secretariado em setores públicos; política, organização e sindicalização secretarial; línguas estrangeiras no trabalho secretarial; outros;

b) teorias organizacionais - gestão secretarial; sistemas gerenciais de informação e computação; gestão dos recursos da informação nas assessorias; assessorias de recursos humanos; gestão de eventos, cerimonial e protocolo; desenvolvimento gerencial em secretariado; assessoria de marketing; assessoria estratégica; empreendedorismo secretarial; assessoria em gestão internacional; assessoria financeira e contábil; gestão da qualidade em assessoria executiva; outros;

c) teorias conceituais: formação intelectual do assessor; educação em secretariado; assessoria científica; teorias de pesquisa e publicação nas assessorias; metodologia científica para estudos secretariais; história do secretariado; ética e responsabilidade social em secretariado; Direito e legislação em secretariado; identidade e cultura profissional; teorias de extensão acadêmica nas assessorias; paradigmas científicos e secretariado; secretariado e Filosofia; outros;

d) teorias interdisciplinares - dimensões psíquicas e emocionais do secretariado; processos interpessoais e intrapessoais no trabalho dos assessores; assessoria em outras ciências e profissões; ciências da informação e secretariado; consultoria e assessoria; Sociologia e assessoria; Economia e assessoria; Linguística e assessoria; assessoria holística; assessoria em gestão de saúde; assessoria jurídica; assessoria em comunicação social; atividades do setor em trabalhos de campo; assessoria em gestão ambiental; a atuação das assessorias em áreas correlatas; outros.

Portanto, a área secretarial tem uma gama de possibilidades de pesquisa nesses horizontes, desde que a realize de forma séria, em contexto epistemológico e metodológico pertinente. Não apenas isso, mas é preciso primar pelo fortalecimento de linhas específicas, com sinergia entre os 
Estado da arte e o rumo do conhecimento científico em secretariado executivo: mapeamento e análise de áreas de pesquisa

pesquisadores, discutindo os problemas relacionados à atuação profissional, questões teóricas e também realizando pesquisas relacionadas com as outras áreas em que o Secretariado dialoga.

\section{PROCEDIMENTOS METODOLÓGICOS}

Considerando-se a natureza do problema a ser verificado, utilizamos a metodologia no contexto da abordagem quantitativa, por meio da estratégia de levantamento de dados em bases secundárias. Quanto à classificação da pesquisa com base nos objetivos, utilizamos os tipos de estudo exploratório e descritivo.

A abordagem quantitativa é aquela que utiliza o levantamento (survey) como estratégia de pesquisa, proporcionando descrição numérica de tendências, atitudes ou opiniões de uma população no estudo de amostra (Creswell, 2007). A estratégia de levantamento é caracterizada "[...] pelo emprego da quantificação tanto nas modalidades de coleta de informações, quanto no tratamento delas por meio de técnicas estatísticas [...]” (Richardson, 2008, p. 70)

O estudo também foi exploratório por ser considerado um assunto em que há pouco conhecimento sobre o tema, proporcionando maior familiaridade com o problema e tornando-o mais explícito. Seu intuito não é o de resolver o problema em si, mas levantar informações que ajudem a entendê-lo melhor. (Gil, 2007; Michel, 2005). Ao mesmo tempo, o estudo é caracterizado como descritivo por apresentar um relato detalhado, envolvendo sua configuração, estrutura, mudanças e relacionamentos com outros fenômenos. Procura ilustrar a complexidade da situação e os aspectos nela envolvidos, apresentando informações sobre assuntos pouco estudados. (Godoi; Bandeira-de-Mello; Silva, 2006)

Para a coleta de dados, utilizamos as técnicas de pesquisa bibliográfica e levantamento de dados em bases secundárias, pois o propósito do estudo foi analisar a produção científica de profissionais formados em Secretariado Executivo. A pesquisa bibliográfica foi utilizada no levantamento do aparato teórico, e o levantamento de dados secundários foi realizado em bases de acesso público, do Conselho Nacional de Desenvolvimento Científico e Tecnológico (CNPq), da Coordenação de Aperfeiçoamento de Pessoal (Capes) e do Google Acadêmico®.

A coleta de dados principal para a pesquisa foi realizada por meio da Plataforma Lattes do CNPq (2013), com a busca nos currículos de profissionais formados em Secretariado Executivo. No sítio eletrônico da Capes, buscamos a estratificação da qualidade da produção científica, através do sistema WebQualis (Capes, 2013b), também a tabela de áreas de conhecimento (Capes, 2013a)

Revista de Gestão e Secretariado - GeSec, São Paulo, v. 4, n. 3, p 157-188, dez. 2013. 
e a pontuação de cada publicação (Capes, 2009). Como a área de Secretariado Executivo não está inserida no Qualis Periódico, consideramos a estratificação das seguintes áreas: administração, ciências contábeis e turismo; interdisciplinar; e ciências sociais aplicadas I. No caso de a publicação não ter Qualis nessas áreas, e sim em outras, a utilização se deu pelo enquadramento do tema do artigo na área existente no Qualis. No Google Acadêmico®, realizamos algumas buscas de artigos para melhor análise da sua área/tema de inserção.

Ressaltamos que as publicações que foram classificadas em outras áreas de conhecimento que não a de Secretariado Executivo - não tinham relação alguma com esta, ou seja, são estudos totalmente realizados no contexto de demandas de várias outras áreas do conhecimento. Os trabalhos que faziam algum tipo de relação com a área de Secretariado Executivo foram enquadrados nesta área. Essas buscas e análises foram realizadas no período de 15 de julho a 19 de agosto de 2013.

Por fim, realizamos o tratamento, análise e interpretação das evidências por meio de técnicas estatísticas descritivas, para o detalhamento da amostra, principalmente com o uso de médias e percentuais, mas também com cálculos um pouco mais complexos. Para tanto, utilizamos o pacote estatístico SPSS ${ }^{\circledR}$ (Statistical Package for the Social Sciences) e também o software Excel ${ }^{\circledR}$, da Microsoft $^{\circledR}$.

\section{APRESENTAÇÃO E ANÁLISE DE DADOS}

No sistema da Plataforma Lattes (CNPq, 2013), para a busca dos currículos, utilizamos o termo de busca "secretariado executivo", como frase exata. Com isso, levantamos um total de 1.614 currículos, os quais foram acessados para verificação e utilização somente daqueles que possuíam a graduação concluída em Secretariado Executivo, totalizando 617 currículos. No entanto, fizemos outra seleção em função dos objetivos do estudo e utilizamos somente aqueles que apresentaram produção bibliográfica, verificada no período de 1988 a agosto de 2013. Sendo assim, os currículos selecionados como amostra com esse perfil totalizaram 219 profissionais vinculados a instituições/empresas de todas as regiões do Brasil.

Inicialmente, apresentaremos alguns dados de perfil desses profissionais, para depois iniciar a análise em torno das publicações científicas. A amostra é composta por 199 profissionais do sexo feminino (aproximadamente 91\%) e 20 do masculino (cerca de 9\%). Esse pequeno percentual do sexo masculino na profissão é um dado oficial, pois no último Censo da Educação Superior de

Revista de Gestão e Secretariado - GeSec, São Paulo, v. 4, n. 3, p 157-188, dez. 2013. 
Estado da arte e o rumo do conhecimento científico em secretariado executivo: mapeamento e análise de áreas de pesquisa

2011 (Inep, 2013) foi encontrado valor parecido, cerca de 8,8\% dos matriculados nos cursos de todo o país.

A Figura 1 apresenta o gráfico comparativo da titulação dos profissionais participantes da amostra. Com esse gráfico é possível observar que, dos formados em Secretariado Executivo, que possuem produção científica, 26,9\% ainda não têm algum tipo de pós-graduação concluída. No entanto, no levantamento dos dados, verificamos que boa parte desses profissionais já está inserida em algum curso de especialização ou mestrado, mas ainda sem conclusão.

Figura 1 - Gráfico comparativo da titulação dos profissionais formados em Secretariado Executivo - Brasil $-2013$

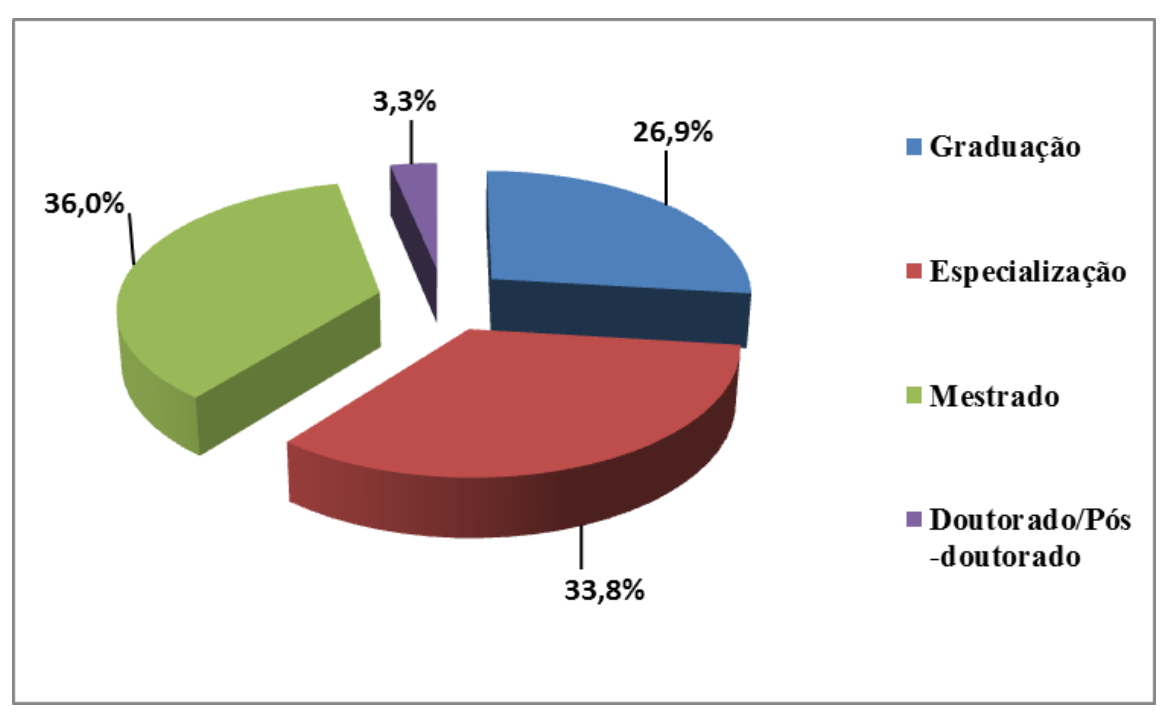

Fonte: elaborada pelos autores, com dados do CNPq (2013).

Os dados da Figura 1 ainda mostram que a maior parte dos profissionais analisados busca por qualificação na pós-graduação stricto sensu (39,3\%). Assim, nota-se o esforço dessa busca, o que tem refletido na evolução quantitativa nos números, se compararmos com estudo anterior (Maçaneiro, 2012), em que os que possuíam mestrado e doutorado ficaram bem abaixo desse percentual $(16,1 \%)$.

Para um detalhamento maior dessa titulação, a formação acadêmica por área de conhecimento está apresentada na Tabela 1. Ressaltamos que a ponderação adotada para inclusão nesta análise foi a utilização da maior titulação da pessoa.

Revista de Gestão e Secretariado - GeSec, São Paulo, v. 4, n. 3, p 157-188, dez. 2013. 
Tabela 1 - Formação acadêmica dos graduados em Secretariado Executivo - Brasil - 2013

\begin{tabular}{|c|c|c|c|c|}
\hline CURSO/ÁREA DE CONHECIMENTO & & NT. & & \\
\hline Somente graduação & 59 & 59 & 26,9 & 26,9 \\
\hline Especialização na área de Secretariado & 16 & \multirow{4}{*}{74} & 7,3 & \multirow{4}{*}{33,8} \\
\hline Especialização na área de Educação & 18 & & 8,2 & \\
\hline Especialização na área de Administração & 31 & & 14,2 & \\
\hline Especialização em outras áreas & 9 & & 4,1 & \\
\hline Mestrado na área de Educação & 22 & \multirow{6}{*}{79} & 10,0 & \multirow{6}{*}{36,0} \\
\hline Mestrado na área de Administração & 23 & & 10,5 & \\
\hline Mestrado na área de Letras & 9 & & 4,1 & \\
\hline Mestrado na área de Economia & 8 & & 3,7 & \\
\hline Mestrado na Área de Engenharia da Produção & 4 & & 1,8 & \\
\hline Mestrado em outras áreas & 13 & & 5,9 & \\
\hline Doutorado na Área de Educação & 1 & \multirow{3}{*}{6} & 0,5 & \multirow{3}{*}{2,8} \\
\hline Doutorado na Área de Administração & 4 & & 1,8 & \\
\hline Doutorado na Área de Letras & 1 & & 0,5 & \\
\hline Pós-Doutorado na Área de Administração & 1 & 1 & 0,5 & 0,5 \\
\hline TOTAL & 219 & 219 & $100 \%$ & $100 \%$ \\
\hline
\end{tabular}

Fonte: elaborada pelos autores, com dados do CNPq (2013).

Revista de Gestão e Secretariado - GeSec, São Paulo, v. 4, n. 3, p 157-188, dez. 2013. 
Estado da arte e o rumo do conhecimento científico em secretariado executivo: mapeamento e análise de áreas de pesquisa

Os resultados da Tabela 1 mostram que, daqueles que possuem somente especialização, boa parte está inserida em outras áreas, fora da de Secretariado, perfazendo um percentual das demais áreas juntas de 26,5\%, em relação a 7,3\% que se encontram na área de Secretariado, do total de currículos analisados. Um aspecto interessante apresentado é o elevado número de profissionais do Secretariado Executivo que buscam sua qualificação nas áreas de Administração e Educação. Essas duas áreas correspondem a 62,5\%, em relação ao total de profissionais que buscaram qualificação além da graduação. Há também uma ligeira preferência pela qualificação na área de Administração (36,9\%), o que pode indicar uma maior vinculação da área de Secretariado com essa área, em detrimento às demais verificadas.

Outro dado de perfil é a região de atuação desses profissionais, conforme apresentado na Tabela 2.

Tabela 2 - Região de atuação dos graduados em Secretariado Executivo - Brasil - 2013

\begin{tabular}{|l|c|c|}
\hline \multicolumn{1}{|c|}{ REGIÃO } & QUANTIDADE & \% \\
\hline Norte & 19 & 8,7 \\
\hline Nordeste & 46 & 21,0 \\
\hline Centro-Oeste & 10 & 4,6 \\
\hline Sudeste & 37 & 16,9 \\
\hline Sul & 107 & 48,8 \\
\hline TOTAL & 219 & $100 \%$ \\
\hline
\end{tabular}

Fonte: elaborada pelos autores, com dados do CNPq (2013).

Verificamos que maior quantidade de profissionais da amostra se encontra na região Sul, seguida do Nordeste e depois do Sudeste. Era de se esperar que houvesse maior concentração de atuação desses profissionais na Região Sudeste, uma vez que concentra maior quantidade de empresas/instituições e possui atividade econômica mais significativa em relação aos demais estados do país. Além disso, o Sudeste também é a região que concentra o maior número de cursos

Revista de Gestão e Secretariado - GeSec, São Paulo, v. 4, n. 3, p 157-188, dez. 2013. 
da área de Secretariado Executivo. De acordo com dados levantados no site do Ministério da Educação (MEC, 2013), dos 276 cursos da área em atividade no Brasil, temos a seguinte quantidade por regiões do país: a) Sudeste com 91 cursos; b) Nordeste com 60 cursos; c) Sul com 51 cursos; d) Centro-Oeste com 46 cursos; e e) Norte com 28 cursos. Dentre esses cursos estão as modalidades presenciais e a distância, os bacharelados, tecnólogos e sequenciais.

Destacamos aqui também que, limitando-se a amostra, a região Sul conta com quatro profissionais qualificados em nível de doutorado e um em nível de pós-doutorado, contra apenas um doutor na região Sudeste e um na região Nordeste. No caso dos profissionais qualificados em nível de mestrado, na região Sul estão $42 \%$ destes, contra $28 \%$ na região Nordeste, $20 \%$ na região Sudeste, $6 \%$ na região Centro-Oeste e $4 \%$ na região Norte.

Tendo esses resultados preliminares de perfil dos profissionais da amostra, passamos a analisar a produção acadêmica que é o objetivo deste estudo. Verificamos que os currículos analisados traziam uma produção bibliográfica realizada entre os anos de 1988 a agosto de 2013. O volume de produção durante esse período consta na Figura 2.

Figura 2 - Volume da produção bibliográfica por ano - 1988 a 2013

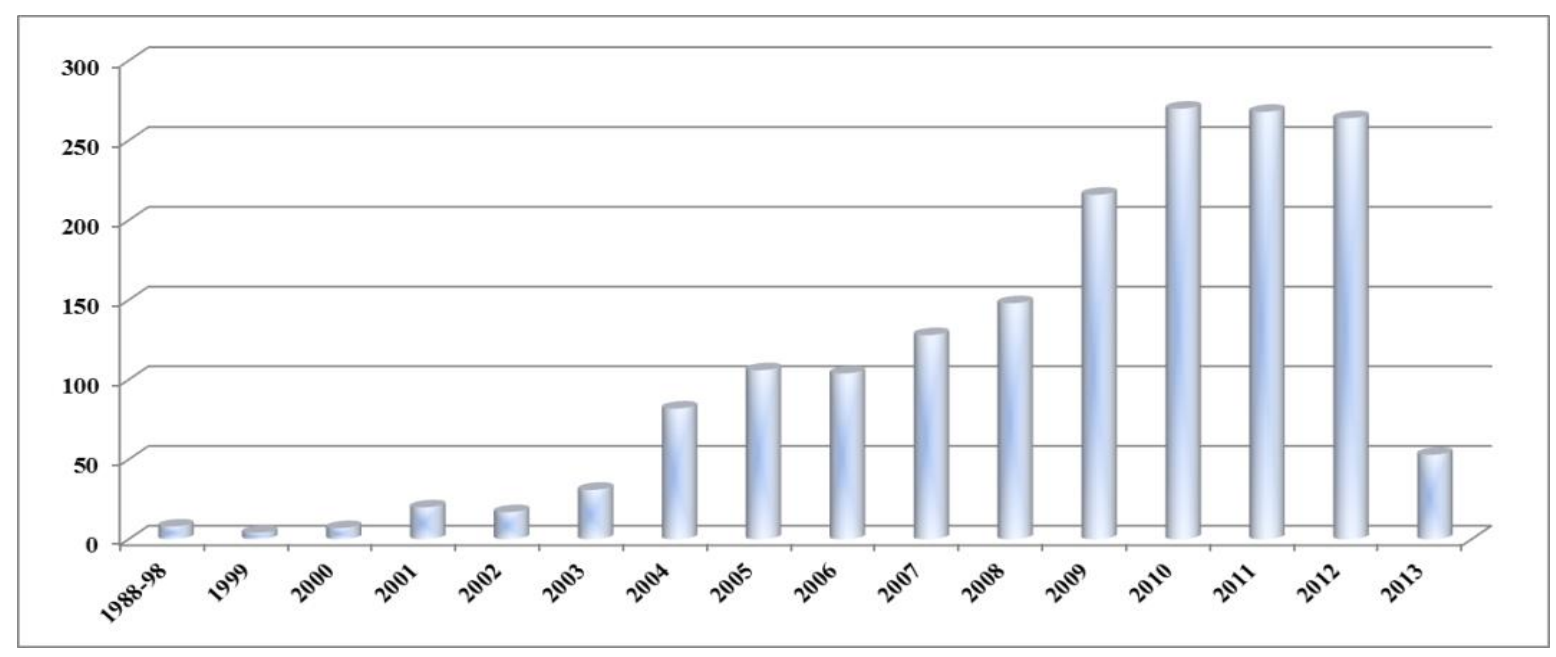

Fonte: elaborada pelos autores, com dados do CNPq (2013).

O gráfico representado na Figura 2 evidencia o crescimento significativo ocorrido no decorrer dos anos, especialmente a partir de 2004, atingindo um patamar relativamente estabilizado nos anos de 2010 a 2012. Talvez esse resultado possa ser atribuído às discussões realizadas no $1^{\circ}$ Encontro Nacional Acadêmico em Secretariado Executivo (Enasec), ocorrido em 2010, sobre as inquietudes que permeiam a produção científica da área e também outros eventos ocorridos a partir

Revista de Gestão e Secretariado - GeSec, São Paulo, v. 4, n. 3, p 157-188, dez. 2013. 
Estado da arte e o rumo do conhecimento científico em secretariado executivo: mapeamento e análise de áreas de pesquisa

desse período, tais como: Congresso Internacional de Secretariado (Coins), Congresso Nacional de Secretariado (Consec), Simpósio Internacional de Secretariado (Simisec), Encontro Nacional de Estudantes de Secretariado (Enesec), dentre outros. Já o ano de 2013 apresenta um volume bastante abaixo do de 2012, mas este fato se justifica pela coleta de dados ter ocorrido no início do segundo semestre de 2013, pela desatualização de muitos dos currículos na base de dados e pelo número relevante de eventos e publicações a se concretizarem até o final do ano.

Essa produção bibliográfica foi verificada conforme os tipos disponíveis na Plataforma Lattes (CNPq, 2013), ou seja: livros publicados (73 unidades), capítulos de livros (121 unidades), artigos completos publicados em periódicos (401 unidades), trabalhos completos em anais de congressos (637 unidades), resumos expandidos em anais de congressos (160 unidades) e resumos em anais de congressos (334 unidades). Essas unidades correspondem a um total de 1.726 itens. No gráfico-teia da Figura 3 aparecem os quatro tipos em maior número dessas publicações levantadas, por ano de análise.

Figura 3 - Tipos de produção bibliográfica por ano - 1988 a 2013

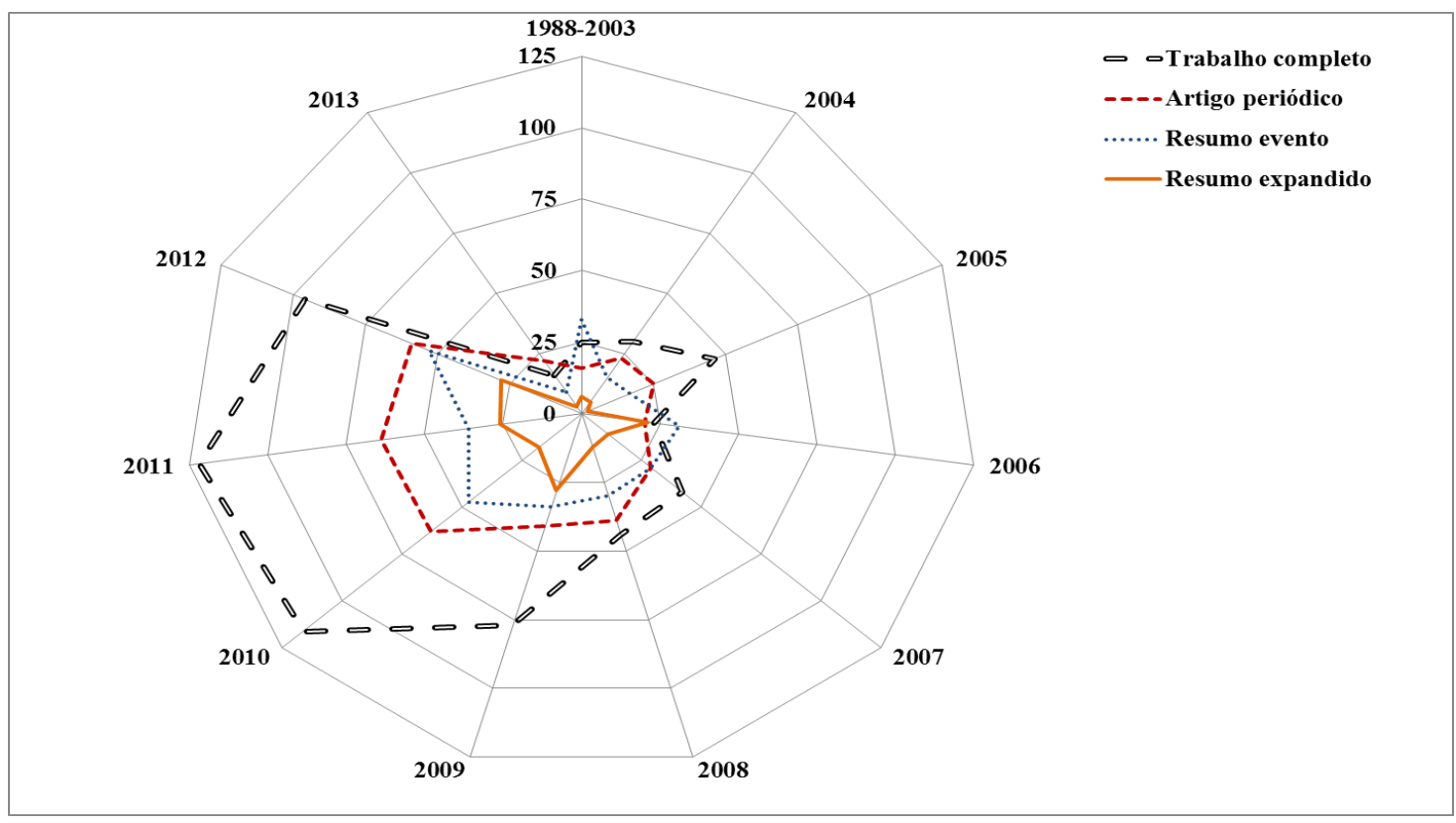

Fonte: elaborada pelos autores, com dados do CNPq (2013).

Verificamos no gráfico que o maior volume é de trabalho completo em eventos, seguido de artigos em periódicos, no entanto este ainda em bem menor quantidade. Uma providência natural realizada pelos pesquisadores é a publicação de um artigo completo, inicialmente, em evento e,

Revista de Gestão e Secretariado - GeSec, São Paulo, v. 4, n. 3, p 157-188, dez. 2013. 
posteriormente, em periódico. Isso porque no evento é uma oportunidade de melhoria do trabalho, nas discussões realizadas durante a apresentação. Sendo assim, acreditamos que muitos dos artigos publicados em eventos pelos profissionais da amostra não são enviados a periódicos, perdendo a oportunidade de divulgação da produção e até mesmo de melhoria do seu currículo acadêmico. Ressaltamos que a orientação é de que um mesmo trabalho seja encaminhado apenas a um evento científico e a uma revista, não podendo haver duplicidade de publicação do mesmo artigo, em eventos.

Conforme os números mostrados, o total dessa produção bibliográfica levantada no período, de 1.726 itens, o que corresponde a uma média de 7,88 unidades por profissional, representando menos de uma publicação por ano. No entanto, alguns profissionais acumularam um volume significativo, como é o caso de uma pessoa com 76 unidades e outra com 73 unidades, além de outros sete profissionais com produção entre 40 e 59 unidades. Apenas esses nove profissionais produziram 510 unidades, com uma média de aproximadamente 56 unidades por profissional.

Entretanto, nesses números estão consideradas publicações independentes da área (Administração, Economia, Educação etc.), ou seja, não são apenas publicações na área do Secretariado Executivo. Quando consideradas as publicações específicas da área do Secretariado Executivo, o total fica reduzido para 582 unidades (apenas 33,7\%, aproximadamente, da publicação total levantada) e o restante, 1.144 itens são publicações de outras áreas. O gráfico da Figura 4 apresenta esse volume de produção por ano, fazendo um comparativo do crescimento entre a área de Secretariado Executivo e as demais áreas como um todo, distribuídas no tempo.

Figura 4 - Volume de produção por ano - 1988 a 2013

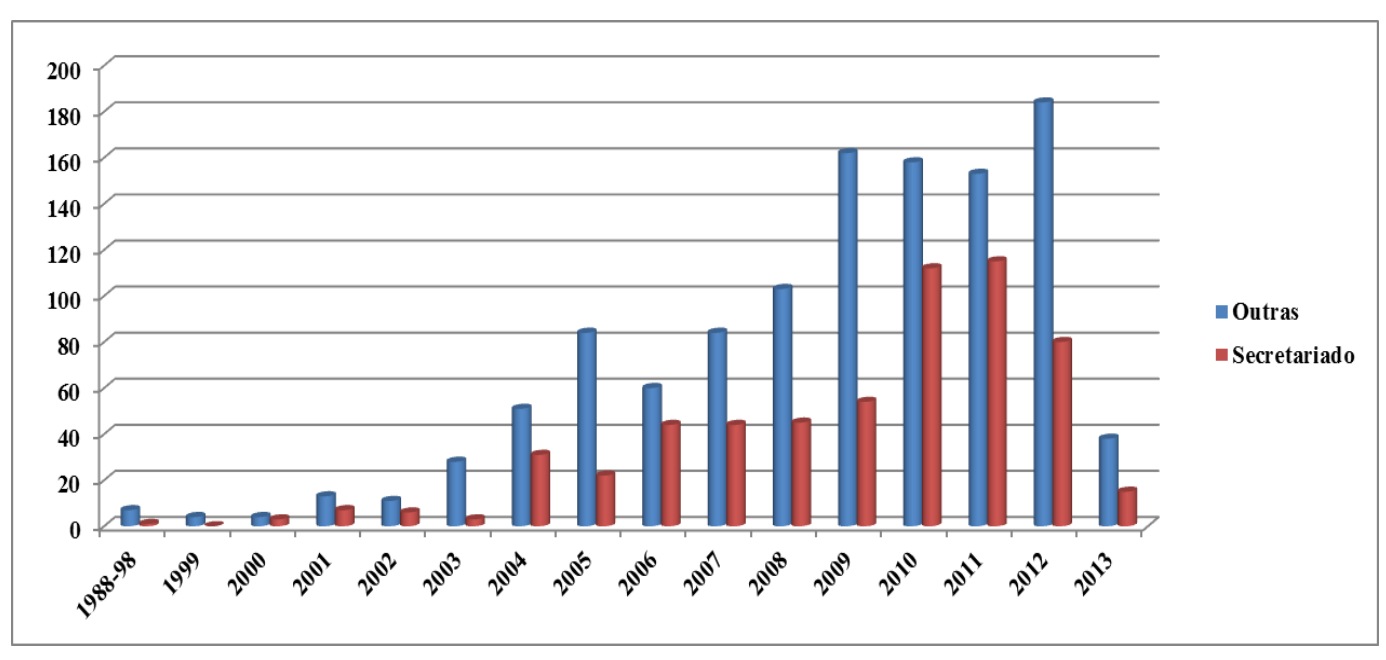

Fonte: elaborada pelos autores, com dados do CNPq (2013). 
Estado da arte e o rumo do conhecimento científico em secretariado executivo: mapeamento e análise de áreas de pesquisa

Na Figura 4 podemos perceber que a produção na área de Secretariado apresentou crescimento mais elevado que as demais áreas nos anos de 2010 e 2011, mas ficando aquém nos anos de 2009 e 2012 e com tendência de ficar abaixo no ano de 2013. Esses dados já indicam que os profissionais de Secretariado Executivo estão publicando mais em outras áreas que na própria, possivelmente um reflexo da titulação, já que profissionais com mestrado, doutorado ou pósdoutorado (teoricamente os mais produtivos em termos de publicações) obtiveram sua titulação em outras áreas. No entanto, adiante ainda serão analisados os dados da publicação, de forma mais pormenorizada.

$\mathrm{Na}$ academia, atualmente, a produção mais valorizada é aquela realizada na forma de artigos publicados em periódicos, preferencialmente com Qualis elevado. O Qualis Periódico é a estratificação da qualidade da produção científica, sendo essa aferição realizada por áreas de avaliação coordenadas pela Capes, que passa por processo anual de atualização. De acordo com a Capes (2013b), "esses veículos são enquadrados em estratos indicativos da qualidade - A1, o mais elevado; A2; B1; B2; B3; B4; B5; C - com peso zero".

Das 1.726 unidades de produção bibliográfica levantadas na amostra, apenas 401 (cerca de 23,2\%) foram realizadas em periódicos, das quais 341 em periódicos com Qualis entre A1 a B5. A Tabela 3 apresenta esses dados.

Tabela 3 - Produção em periódicos por estratificação Qualis - 1988 a 2013

\begin{tabular}{|c|c|c|}
\hline ESTRATIFICAÇÃO & QUANTIDADE & $\%$ \\
\hline A1 & 06 & 1,5 \\
\hline A2 & 13 & 3,2 \\
\hline B1 & 24 & 6,0 \\
\hline B2 & 68 & 16,9 \\
\hline B3 & 43 & 10,7 \\
\hline B4 & 36 & 9,0 \\
\hline B5 & 151 & 37,7 \\
\hline
\end{tabular}

Revista de Gestão e Secretariado - GeSec, São Paulo, v. 4, n. 3, p 157-188, dez. 2013. 


\begin{tabular}{|c|c|c|}
\hline C & 34 & 8,5 \\
\hline Sem Qualis & 26 & 6,5 \\
\hline TOTAL & 401 & $100 \%$ \\
\hline
\end{tabular}

Fonte: elaborada pelos autores, com dados do CNPq (2013) e da Capes (2013b).

Observamos um maior número de produção em periódicos Qualis B5, seguido de uma quantidade menor em B2 e em B3. No entanto, outros 15\% da produção foi realizada em periódicos C e sem Qualis, o que demostra certo esforço em publicações que não geram pontuações qualitativas nos currículos.

Nesse sentido, também é interessante notar que, das publicações na área de Secretariado Executivo (582 unidades), cerca de $28,5 \%$ são em periódicos, totalizando 166 publicações, contra 20,5\% das publicações nas outras áreas (1.144), que totalizam 235 publicações. Porém, das publicações na área em periódicos, 35,7\% foram realizadas em Qualis B5 ou superior, contra 49,4\% das publicações em outras áreas. Nenhuma publicação da área foi realizada em periódico A1 ou A2, e apenas uma em periódico Qualis B1. Sendo assim, inferimos que parece existir a tendência de publicação em periódicos na área de Secretariado, porém ainda incipiente nas revistas com maior estratificação. É provável que a justificativa esteja no fato de termos poucos periódicos na área e apenas uma revista com Qualis B2 e uma com B3 e as demais B5 e C.

Para um detalhamento da pontuação oriunda dessa publicação em periódicos, a Figura 5 apresenta um gráfico onde estão indicadas as pontuações médias, segundo o critério Qualis, agrupadas de acordo com a titulação. A pontuação da publicação em periódicos é definida por área de avaliação da Capes. Nesta análise, foi utilizada a área de Administração, Ciências Contábeis e Turismo, na qual a pontuação dos artigos é a seguinte: periódico com estratificação A1 = 100 pontos; $\mathrm{A} 2=80 ; \mathrm{B} 1=60 ; \mathrm{B} 2=50 ; \mathrm{B} 3=30 ; \mathrm{B} 4=20 ; \mathrm{B} 5=10 ; \mathrm{e} \mathrm{C}=0$ (Capes, 2009). 
Estado da arte e o rumo do conhecimento científico em secretariado executivo: mapeamento e análise de áreas de pesquisa

Figura 5 - $\quad$ Pontuações médias das publicações em periódicos, segundo o critério Qualis, por titulação dos profissionais.

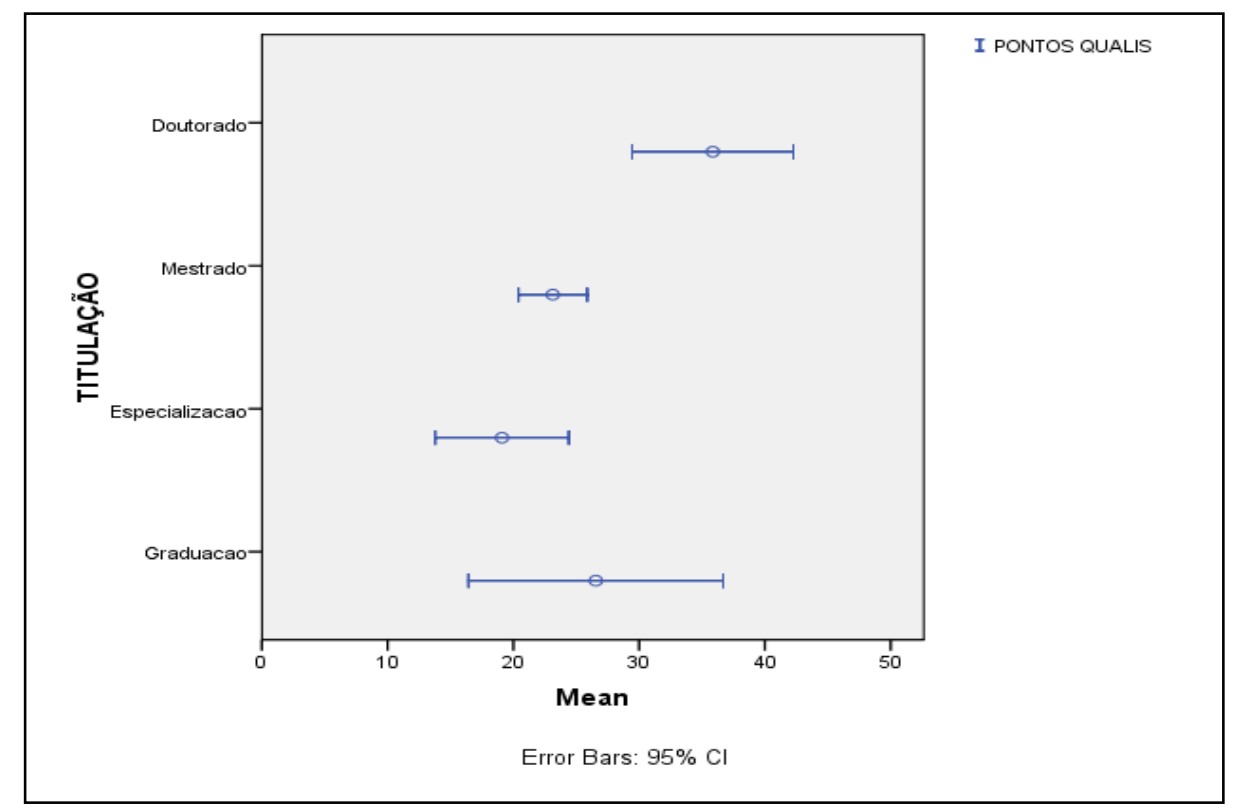

Fonte: elaborada pelos autores, com dados do $\operatorname{CNPq}$ (2013) e da Capes (2009, 2013b).

A partir do gráfico da Figura 5, é possível perceber que a média de pontuação dos profissionais com doutorado é significativamente maior que os profissionais com mestrado e especialização. As médias são estatisticamente diferentes, segundo a Análise da Variância (Anova) com significância de 5\% (p < 0,05), para estes profissionais. A Anova serve para testar se as médias de mais de duas populações são ou não significativamente diferentes. (Hair Jr. et al., 2005, p. 297; Malhotra, 2006, p. 467; Maroco, 2003, p. 127). No entanto, não existe diferença estatística entre os profissionais com doutorado e com graduação. Este resultado pode estar associado ao pequeno número de profissionais com graduação e que obtiveram pontuação Qualis, apenas 29 deles.

Tendo esses resultados, passamos a analisar a produção científica levantada em relação à titulação dos profissionais, que é a principal análise inserida nos objetivos do estudo. A Tabela 4 apresenta esses dados.

Revista de Gestão e Secretariado - GeSec, São Paulo, v. 4, n. 3, p 157-188, dez. 2013. 
Tabela 4 - Publicações em relação à titulação e à área da publicação - 1988 a 2013

\begin{tabular}{|c|c|c|c|c|c|c|c|c|c|}
\hline Titulação & $\begin{array}{c}\text { Área da } \\
\text { publicação }\end{array}$ & $\begin{array}{c}\text { Livro } \\
\text { completo }\end{array}$ & $\begin{array}{l}\text { Capítulo } \\
\text { de livro }\end{array}$ & $\begin{array}{l}\text { Artigo em } \\
\text { periódico }\end{array}$ & $\begin{array}{c}\text { Trabalho } \\
\text { completo } \\
\text { em evento }\end{array}$ & $\begin{array}{c}\text { Resumo } \\
\text { expandido } \\
\text { em evento }\end{array}$ & $\begin{array}{c}\text { Resumo } \\
\text { em } \\
\text { evento }\end{array}$ & $\begin{array}{c}\text { Total de } \\
\text { produção }\end{array}$ & $\begin{array}{c}\text { Percentual } \\
\text { por área e } \\
\text { titulação }\end{array}$ \\
\hline \multirow{6}{*}{$\begin{array}{c}\text { Graduaçãao } \\
\text { (26,9\% da } \\
\text { amostra) }\end{array}$} & Secretariado & 2 & 4 & 12 & 22 & 10 & 25 & 75 & 46,9 \\
\hline & $\begin{array}{c}\text { Letras/ } \\
\text { Linguística }\end{array}$ & 0 & 1 & 7 & 10 & 2 & 20 & 40 & 25,0 \\
\hline & Administração & 0 & 1 & 3 & 12 & 4 & 0 & 20 & 12,5 \\
\hline & Economia & 0 & 0 & 6 & 2 & 1 & 0 & 9 & 5,6 \\
\hline & Outras & 0 & 2 & 1 & 8 & 1 & 4 & 16 & 10,0 \\
\hline & Subtotal & 2 & 8 & 29 & 54 & 18 & 49 & 160 & $9,2 \%$ \\
\hline \multirow{6}{*}{$\begin{array}{c}\text { Especialização } \\
(33,8 \% \text { da } \\
\text { amostra })\end{array}$} & Secretariado & 2 & 7 & 43 & 44 & 6 & 42 & 144 & 55,4 \\
\hline & Administração & 1 & 4 & 9 & 17 & 7 & 14 & 52 & 20,0 \\
\hline & Educação & 2 & 2 & 5 & 3 & 1 & 3 & 16 & 6,1 \\
\hline & $\begin{array}{c}\text { Letras/ } \\
\text { Linguística }\end{array}$ & 0 & 2 & 2 & 3 & 1 & 6 & 14 & 5,4 \\
\hline & Outras & 2 & 1 & 7 & 15 & 3 & 6 & 34 & 13,1 \\
\hline & Subtotal & 7 & 16 & 66 & 82 & 18 & 71 & 260 & $15,1 \%$ \\
\hline \multirow{7}{*}{$\begin{array}{l}\text { Mestrado } \\
\text { (36\% da } \\
\text { amostra) }\end{array}$} & Secretariado & 21 & 23 & 94 & 88 & 37 & 45 & 308 & 30,7 \\
\hline & Administração & 17 & 18 & 59 & 121 & 27 & 23 & 265 & 26,4 \\
\hline & $\begin{array}{c}\text { Letras/ } \\
\text { Linguística }\end{array}$ & 4 & 4 & 23 & 42 & 8 & 57 & 138 & 13,7 \\
\hline & Educação & 9 & 20 & 21 & 40 & 3 & 18 & 111 & 11,1 \\
\hline & Economia & 1 & 1 & 12 & 34 & 1 & 1 & 50 & 5,0 \\
\hline & Outras & 1 & 14 & 27 & 62 & 7 & 21 & 132 & 13,1 \\
\hline & Subtotal & 53 & 80 & 236 & 387 & 83 & 165 & 1.004 & $58,2 \%$ \\
\hline
\end{tabular}


Estado da arte e o rumo do conhecimento científico em secretariado executivo: mapeamento e análise de áreas de pesquisa

\begin{tabular}{|c|c|c|c|c|c|c|c|c|c|}
\hline Titulação & $\begin{array}{c}\text { Área da } \\
\text { publicação }\end{array}$ & $\begin{array}{c}\text { Livro } \\
\text { completo }\end{array}$ & $\begin{array}{l}\text { Capítulo } \\
\text { de livro }\end{array}$ & $\begin{array}{c}\text { Artigo em } \\
\text { periódico }\end{array}$ & $\begin{array}{c}\text { Trabalho } \\
\text { completo } \\
\text { em evento }\end{array}$ & $\begin{array}{c}\text { Resumo } \\
\text { expandido } \\
\text { em evento }\end{array}$ & $\begin{array}{c}\text { Resumo } \\
\text { em } \\
\text { evento }\end{array}$ & $\begin{array}{c}\text { Total de } \\
\text { produção }\end{array}$ & $\begin{array}{c}\text { Percentual } \\
\text { por área e } \\
\text { titulação }\end{array}$ \\
\hline \multirow{7}{*}{$\begin{array}{c}\text { Doutorado/ } \\
\text { Pós-doutorado } \\
\text { (3,3\% da } \\
\text { amostra) }\end{array}$} & Administração & 2 & 8 & 24 & 49 & 14 & 12 & 109 & 36,1 \\
\hline & $\begin{array}{c}\text { Letras/ } \\
\text { Linguística }\end{array}$ & 6 & 6 & 11 & 12 & 1 & 27 & 63 & 20,9 \\
\hline & Secretariado & 0 & 3 & 17 & 10 & 15 & 10 & 55 & 18,2 \\
\hline & Economia & 2 & 0 & 10 & 31 & 4 & 0 & 47 & 15,5 \\
\hline & Educação & 1 & 0 & 4 & 8 & 0 & 0 & 13 & 4,3 \\
\hline & Outras & 0 & 0 & 4 & 4 & 7 & 0 & 15 & 5,0 \\
\hline & Subtotal & 11 & 17 & 70 & 114 & 41 & 49 & 302 & $17,5 \%$ \\
\hline \multicolumn{2}{|c|}{ TOTAL } & 73 & 121 & 401 & 637 & 160 & 334 & 1.726 & $100 \%$ \\
\hline
\end{tabular}

Fonte: elaborada pelos autores, com dados do CNPq (2013).

Inicialmente, os números mostram uma relação já esperada, em que, na medida em que os profissionais se qualificam, o quantitativo da produção científica aumenta. Se compararmos os percentuais de titulação da amostra, inseridos na primeira coluna da Tabela 4, aos quantitativos da publicação, veremos que os percentuais de publicação ficam bem acima dos da titulação nos níveis de mestrado (36\% compõem a titulação de mestre e realizam 58,2\% das publicações) e de doutorado/pós-doutorado (3,3\% compõem a titulação de doutor e realizam 17,5\% das publicações). Ao contrário, esses percentuais ficam bem abaixo nos níveis da graduação $(26,9 \%$ tem apenas a graduação e realizam $9,2 \%$ das publicações) e da especialização (33,8\% são especialistas e realizam $15,1 \%$ das publicações).

Quanto à relação entre o nível de titulação e a área da publicação da amostra, as análises trazem algumas questões importantes e que se inserem nos objetivos deste estudo. Nos níveis de titulação mais inferiores, as publicações refletem em maior número na área de Secretariado Executivo, tais como na graduação $(46,9 \%)$ e na especialização $(55,4 \%)$. Ao contrário, no nível de mestrado a área de Secretariado tem uma queda na publicação $(30,7 \%)$ e no doutorado esse percentual está bem abaixo do que nos anteriores (18,2\%). Esse resultado nos faz confirmar a

Revista de Gestão e Secretariado - GeSec, São Paulo, v. 4, n. 3, p 157-188, dez. 2013. 
hipótese de que as publicações realizadas por profissionais com nível de mestrado e doutorado são realizadas, em sua maioria, em outras áreas que não as de Secretariado Executivo.

Outra análise que pode ser feita é das áreas em que mais são produzidos trabalhos, em todos os níveis de titulação. A área de Secretariado aparece com 33,7\% de todas as publicações, Administração com 25,8\% e Letras/Linguística com 14,8\%. As outras áreas perfizeram um total de 25,7\%, sendo elas: Ciência da Informação, Ciências Agrárias, Ciências Ambientais, Ciências da Religião, Ciências da Saúde, Ciências Sociais, Comunicação, Direito, Economia, Educação, Engenharia da produção, Filosofia, Políticas Públicas, Relações Internacionais e Turismo. Ressaltamos, nesse aspecto, que os trabalhos publicados nessas outras áreas não tinham relação alguma com a de Secretariado, ou seja, são estudos totalmente realizados no contexto de demandas dessas várias áreas do conhecimento.

Por fim, o detalhamento dos trabalhos publicados na área de Secretariado, por teoria e subárea, encontra-se na Tabela 5. Para esse detalhamento, foi utilizado o agrupamento pela classificação realizada por Nonato Júnior (2009, pp. 191-192), categorizada por teorias e o que nós denominamos de subáreas em que a produção do conhecimento em Secretariado se concentra. Ressaltamos que algumas inclusões foram realizadas nessa classificação, em função de trabalhos publicados que não se enquadravam nas subáreas originais, as quais foram destacadas na Tabela com asterisco.

Revista de Gestão e Secretariado - GeSec, São Paulo, v. 4, n. 3, p 157-188, dez. 2013. 
Estado da arte e o rumo do conhecimento científico em secretariado executivo: mapeamento e análise de áreas de pesquisa

Tabela 5 - Produção por teorias e subáreas dos trabalhos publicados na área de Secretariado Executivo 1988 a 2013

\begin{tabular}{|c|c|c|c|}
\hline TEORIAS & QUANT. & SUBÁREAS & QUANT. \\
\hline \multirow{11}{*}{ Teorias profissionais } & \multirow{11}{*}{173} & Técnicas do trabalho secretarial & 21 \\
\hline & & Tecnologia secretarial & 3 \\
\hline & & Documentação, correspondência e registro & 6 \\
\hline & & Arquivística, classificação e catalogação & 12 \\
\hline & & Organização \& métodos secretariais & 5 \\
\hline & & Secretariado em setores públicos & 7 \\
\hline & & Política, organização e sindicalização secretarial & 3 \\
\hline & & Línguas estrangeiras no trabalho secretarial & 14 \\
\hline & & Perfil profissional e empregabilidade * & 60 \\
\hline & & Administração do tempo secretarial * & 3 \\
\hline & & Tendências e evolução da atuação profissional * & 39 \\
\hline \multirow{6}{*}{$\begin{array}{c}\text { Teorias } \\
\text { organizacionais }\end{array}$} & \multirow{6}{*}{117} & Gestão secretarial & 25 \\
\hline & & Sistemas gerenciais de informação e computação & 5 \\
\hline & & Gestão dos recursos da informação nas assessorias & 10 \\
\hline & & Assessorias de recursos humanos & 11 \\
\hline & & Gestão de eventos, cerimonial e protocolo & 25 \\
\hline & & Desenvolvimento gerencial em secretariado & 15 \\
\hline
\end{tabular}

Revista de Gestão e Secretariado - GeSec, São Paulo, v. 4, n. 3, p 157-188, dez. 2013. 


\begin{tabular}{|c|c|c|c|}
\hline TEORIAS & QUANT. & SUBÁREAS & QUANT. \\
\hline & & Assessoria de marketing & 7 \\
\hline & & Empreendedorismo secretarial & 12 \\
\hline & & Assessoria em gestão internacional & 3 \\
\hline & & Assessoria financeira e contábil & 3 \\
\hline & & Gestão da qualidade em assessoria executiva & 1 \\
\hline \multirow{11}{*}{ Teorias conceituais } & \multirow{11}{*}{229} & Formação intelectual do assessor & 14 \\
\hline & & Educação em secretariado & 102 \\
\hline & & Assessoria científica & 1 \\
\hline & & Teorias de pesquisa e publicação nas assessorias & 34 \\
\hline & & Metodologia científica para estudos secretariais & 8 \\
\hline & & História do secretariado & 3 \\
\hline & & Ética e responsabilidade social em secretariado & 32 \\
\hline & & Identidade e cultura profissional & 7 \\
\hline & & Teorias de extensão acadêmica nas assessorias & 10 \\
\hline & & Paradigmas científicos \& secretariado & 5 \\
\hline & & Relações de gênero e representações sociais * & 13 \\
\hline $\begin{array}{l}\text { Teorias } \\
\text { interdisciplinares }\end{array}$ & 63 & Dimensões psíquicas e emocionais do secretariado & 6 \\
\hline
\end{tabular}


Estado da arte e o rumo do conhecimento científico em secretariado executivo: mapeamento e análise de áreas de pesquisa

\begin{tabular}{|c|c|c|c|}
\hline TEORIAS & QUANT. & SUBÁREAS & QUANT. \\
\hline & & $\begin{array}{l}\text { Processos interpessoais e intrapessoais no trabalho dos } \\
\text { assessores }\end{array}$ & 2 \\
\hline & & Assessoria em outras ciências e profissões & 2 \\
\hline & & Ciências da informação \& secretariado & 6 \\
\hline & & Consultoria e assessoria & 14 \\
\hline & & Economia e assessoria & 2 \\
\hline & & Linguística e assessoria & 10 \\
\hline & & Assessoria jurídica & 1 \\
\hline & & Assessoria em comunicação social & 16 \\
\hline & & Assessoria em gestão ambiental & 4 \\
\hline TOTAL & 582 & & 582 \\
\hline
\end{tabular}

* Subáreas acrescidas na classificação de Nonato Júnior (2009).

Fonte: elaborada pelos autores, com dados do CNPq (2013) e subáreas adaptadas de Nonato Júnior (2009).

Pelo apresentado na Tabela 5, nota-se maior concentração de trabalhos realizados na subárea das teorias conceituais (39\%), seguida pelas teorias profissionais (30\%) e teorias organizacionais (20\%), ficando por último as subáreas das teorias interdisciplinares (11\%). Esse resultado, em certa medida, vai ao encontro do alertado por Nonato Júnior (2009, p. 193), quando menciona que “[...] Se nos limitarmos a analisar apenas questões operacionais em Secretariado, estaremos impedindo seu avanço acadêmico e intelectual." Portanto, esse mapeamento apresentado na Tabela 5 revela um número significativo de trabalhos publicados nas teorias conceituais e interdisciplinares, que juntas comportam 50\% das publicações, em detrimento aos trabalhos relacionados aos campos operacionais das organizações (teorias profissionais e teorias organizacionais).

As subáreas que se destacaram em termos de quantitativo de publicação foram: educação em secretariado com 17,5\%; perfil profissional e empregabilidade com 10,3\%; tendências e Revista de Gestão e Secretariado - GeSec, São Paulo, v. 4, n. 3, p 157-188, dez. 2013. 
evolução da atuação profissional com 6,7\%; teorias de pesquisa e publicação nas assessorias com $5,8 \%$; e ética e responsabilidade social em secretariado com 5,5\%. Podemos considerar que esses temas mostram onde estão as preocupações e questionamentos dos formados em Secretariado Executivo, já que trabalhar a pesquisa científica é “[...] toda atividade voltada para a solução de problemas; como atividade de busca, indagação, investigação, inquirição da realidade [...]" (Pádua, 1997, p. 29). Ou seja, os pesquisadores da área estão questionando a sua empregabilidade, que aponta para uma atuação em evolução no momento atual, o que também depende de o campo se firmar enquanto área de conhecimento, mas sempre com uma atuação ética e responsável nas organizações.

\section{CONSIDERAÇÕES FINAIS}

Este estudo teve por objetivo mapear a produção científica dos formados em Secretariado Executivo, no sentido de verificar as áreas e a quantificação pertinentes a essa publicação, bem como analisar a relação entre essa publicação e a titulação dos pesquisados. Para atingir esse objetivo, buscamos no sistema da Plataforma Lattes (CNPq, 2013) os currículos dos profissionais formados em Secretariado Executivo e que possuíam algum tipo de produção científica, totalizando uma amostra de 219 profissionais, vinculados a instituições/empresas de todas as regiões do Brasil.

Traçando um perfil da amostra, verificamos que ela é composta por $91 \%$ de profissionais do sexo feminino e $9 \%$ do masculino. Com relação à titulação, 26,9\% possuem apenas a graduação, 33,8\% com especialização, 36\% com mestrado e 3,3\% possuem doutorado/pós-doutorado. Essa qualificação é realizada principalmente nas áreas de Administração e de Educação. A atuação desses profissionais ocorre em maior número na região Sul do Brasil e essa região é a que concentra os maiores percentuais de qualificação nos níveis de mestrado, doutorado e pós-doutorado.

A produção bibliográfica analisada correspondeu ao período de 1988 a agosto de 2013, num volume total de 1.726 itens, dentre livros, capítulos de livros, artigos completos em periódicos, trabalhos completos em anais de eventos, resumos expandidos e resumos em anais de eventos. Essa produção teve um crescimento significativo ao longo dos anos, a partir de 2004, sendo que 2010 a 2012 foram os que mais tiveram publicações desses profissionais. Talvez isso seja resultado dos vários eventos e reuniões que ocorreram a partir desse período, onde foram manifestadas as inquietudes do Secretariado sobre a produção científica e sua classificação como área de conhecimento.

Revista de Gestão e Secretariado - GeSec, São Paulo, v. 4, n. 3, p 157-188, dez. 2013. 
Outro aspecto verificado no levantamento de dados foi o de que alguns poucos profissionais concentram um número significativo de publicação. Ou seja, a média de produção dos 219 profissionais analisados é de 7,88 unidades, enquanto que nove desses profissionais possuem uma média de aproximadamente 56 unidades. Isso demonstra uma concentração da produção, o que não é benéfico à área, pois deveria haver homogeneidade maior dessas publicações.

Quanto à qualificação da produção, verificamos que apenas 23,2\% foram realizadas em periódicos, sendo que 19,8\% em periódicos com Qualis. Além disso, o Qualis que foi mais utilizado foi o B5, com 37,7\% dessa produção. Os periódicos A1 e A2 foram utilizados somente por 4,7\% da publicação, B1 e B2 por 22,9\% e B3 e B4 por 19,7\%. Isso demonstra que a área de Secretariado ainda não procura uma produção mais qualificada, o que seria imprescindível para a sua cientificidade.

Tendo esses resultados, o estudo também se propôs a analisar a área das publicações, partindo do pressuposto de que há um pequeno número de estudos realizados na área específica do Secretariado, por profissionais com nível de mestrado e doutorado. De um modo geral, os dados mostraram que apenas $33,7 \%$ da produção estão na área de Secretariado ou fazem relação com ela. Além disso, na graduação $(46,9 \%)$ e na especialização $(55,4 \%)$ as publicações refletem em maior número na área de Secretariado Executivo, enquanto que no nível de mestrado a área de Secretariado tem uma queda na publicação $(30,7 \%)$ e no doutorado esse percentual está bem abaixo do que nos anteriores $(18,2 \%)$. Esse resultado confirma a hipótese do estudo, de que as publicações realizadas por profissionais com nível de mestrado e doutorado são realizadas, em sua maioria, em outras áreas que não as de Secretariado Executivo. Ou seja, os profissionais de Secretariado Executivo estão publicando mais em outras áreas que na própria área, possivelmente um reflexo da titulação, já que aqueles com mestrado, doutorado ou pós-doutorado, os que teoricamente são mais produtivos em termos de publicações, obtiveram sua titulação em outras áreas.

A análise das subáreas das publicações do Secretariado mostrou as preocupações e questionamentos dos pesquisadores na resolução de problemas da sua realidade profissional. A publicação da área apresentou trabalhos preocupados com a empregabilidade, a qual possui uma atuação que está em evolução no momento atual, que depende de o campo se firmar enquanto área de conhecimento, mas sempre primando pela ética e responsabilidade social, tanto dessa atuação como das atividades organizacionais.

Com esses resultados, pode-se considerar que, muito embora a maior parte da produção científica dos formados em Secretariado seja em outras áreas do conhecimento, isso possibilita a inserção desses profissionais no bojo da produção científica. O caminho natural é realmente

Revista de Gestão e Secretariado - GeSec, São Paulo, v. 4, n. 3, p 157-188, dez. 2013. 
este: é preciso fortalecer a formação acadêmica em nível stricto sensu, para então poder ser explorados os outros aspectos do "caminho das pedras". Ou seja, um corpo de pesquisadores melhor qualificados, em maior quantidade com título de mestre e doutor, com produção científica densa, abre espaços para o fortalecimento da área de Secretariado Executivo.

Não obstante, a delimitação da cientificidade do Secretariado Executivo somente será realizada por meio de um contexto de produção de conhecimento com qualidade e em "larga escala". Ou seja, perspectivas futuras em termos de indicação da consolidação da cientificidade da área somente serão possíveis a partir do momento em que a área puder compor um corpo de pesquisas sólidas, teóricas, metodológicas e aplicadas. Para isso, vários outros fatores terão de ser consolidados, tais como: maior formação acadêmica no nível de doutorado; criação de mestrado na área específica; criação e qualificação de periódicos científicos; criação e qualificação de eventos científicos; criação e fortalecimento de grupos de pesquisa; interinstitucionalização da pesquisa acadêmica; dentre outros aspectos.

Por fim, é preciso mencionar algumas limitações dos resultados ocorridas neste estudo, que devem ser levadas em consideração. Primeiro o fato de vários currículos não estarem atualizados na base de dados, o que pode levar a um resultado parcial, não representando o quantitativo total das publicações dos profissionais analisados. Outro fato é possivelmente alguns resultados duplicados que podem ter ocorrido, quando da realização de estudos em mais de um profissional formado em Secretariado, pois a busca foi individual e manual em cada currículo, não sendo possível realizar essa verificação da duplicidade.

\section{REFERÊNCIAS}

Bachelard, G. (1996). A formação do espírito científico: contribuição para uma psicanálise do conhecimento. Rio de Janeiro: Contraponto.

. (2001). A epistemologia. (F.de .L. Godinho e M. C. Oliveira, Trad.). Lisboa: Edições 70. (Coleção O Saber da Filosofia).

Bíscoli, F. R. V. (2012). A evolução do secretariado executivo: caminhos prováveis a partir dos avanços da pesquisa científica e dos embates teóricos e conceituais na área. In D. G. Durante (org.), Pesquisa em secretariado: cenários, perspectivas e desafios (pp. 37-74). Passo Fundo: Ed. UPF.

Revista de Gestão e Secretariado - GeSec, São Paulo, v. 4, n. 3, p 157-188, dez. 2013. 
Estado da arte e o rumo do conhecimento científico em secretariado executivo: mapeamento e análise de áreas de pesquisa

Burrel, G., \& Morgan, G. (1979). Sociological paradigms and organizational analysis. (W. Martins, Trad. livre). London: Heineman.

Conselho Nacional de Desenvolvimento Científico e Tecnológico - CNPq (2013). Plataforma Lattes. Retrieved from http://lattes.cnpq.br/.

Coordenação de Aperfeiçoamento de Pessoal de Nível Superior - Capes (2009). Documento de área $2009 . \quad$ Retrieved from http://www.capes.gov.br/images/stories/download/avaliacao/ADMIN17jun10.pdf

(2013a). Tabela de áreas de conhecimento. Retrieved from http://www.capes.gov.br/avaliacao/tabela-de-areas-de-conhecimento

(2013b). Qualis periódicos. Retrieved from http://www.capes.gov.br/avaliacao/qualis

Creswell, J. W. (2007). Projeto de pesquisa: métodos qualitativo, quantitativo e misto (2a ed.). Porto Alegre: Artmed.

Demo, P. (2006). Pesquisa: princípio científico e educativo (12nd ed.). São Paulo: Cortez.

Durante, D. G. (2010). Direções para pesquisas em secretariado executivo e criação de cursos de especialização e mestrado. In $1^{\circ}$ Encontro Nacional Acadêmico de Secretariado Executivo. Anais... Toledo: Unioeste.

. (org.). (2012). Pesquisa em secretariado: cenários, perspectivas e desafios. Passo Fundo: Ed. UPF.

Gil, A. C. (2007). Como elaborar projetos de pesquisa (4a ed.). São Paulo: Atlas.

Godoi, C. K.; Bandeira-de-Mello, R. \& Silva, A. B. da (orgs.) (2006). Pesquisa qualitativa em estudos organizacionais: paradigmas, estratégias e métodos. São Paulo: Saraiva.

Hair Jr., J. F.; Babin, B. \& Money, A. H.; Samouel, P. (2005). Fundamentos de métodos de pesquisa em administração.(L. B. Ribeiro, Trad.). Porto Alegre: Bookman.

Hoeller, P. A. F. (2006). A natureza do conhecimento em Secretariado Executivo. Expectativa, 5(5), 139-145.

Instituto Nacional de Estudos e Pesquisas Educacionais Anísio Teixeira - Inep (2013). Censo da educação superior: 2011 - resumo técnico. Brasília: Inep. 
Maçaneiro, M. B. (2012). A construção da identidade científica em Secretariado Executivo. In D. G. Durante (org.), Pesquisa em secretariado: cenários, perspectivas e desafios (pp. 75-97). Passo Fundo: Ed. UPF.

Malhotra, N. K. (2006). Pesquisa de Marketing: Uma orientação aplicada (L. Bocco, Trad.) (4a ed.) Porto Alegre: Bookman.

Maroco, J. (2003). Análise estatística - com utilização do SPSS (2a ed.). Lisboa: Edições Sílabo.

Martins, C. B.; Genghini, L. A.; Maccari, É. A. \& Genghini, E. B. (2012). Parâmetros para definições de linhas de pesquisas. In D. G. Durante (org.), Pesquisa em secretariado: cenários, perspectivas e desafios (pp. 132-148). Passo Fundo: Ed. UPF.

Matias-Pereira, J. (2007). Manual de metodologia da pesquisa científica. São Paulo: Atlas.

Michel, M. H. (2005). Metodologia e pesquisa científica em Ciências Sociais: um guia prático para acompanhamento da disciplina de elaboração de trabalhos monográficos. São Paulo: Atlas.

Minayo, M. C. de S. (org.); Deslandes, S. F. \& Gomes, R. (2007). Pesquisa social: teoria método e criatividade (25a ed.). Petrópolis: Vozes.

Ministério da Educação - MEC (2013). E-mec - instituições de educação superior e cursos cadastrados. Retrieved from http://emec.mec.gov.br/

Nascimento, E. P. (2012). Pesquisa aplicada e interdisciplinaridade: da linguística ao secretariado. In D. G. Durante (org.), Pesquisa em secretariado: cenários, perspectivas e desafios (pp. 98118). Passo Fundo: Ed. UPF.

Nonato Júnior, R. (2008). Epistemologia do Secretariado Executivo: por uma teoria do conhecimento em Secretariado. In XVI Congresso Nacional de Secretariado. Anais... Brasília: Federação Nacional de Secretariado. $\quad$ Retrieved from http://www.fenassec.com.br/c_artigos_trabalhos_cientificos_xvi_consec.html>

. (2009). Epistemologia e teoria do conhecimento em Secretariado Executivo: a fundação das ciências da Assessoria. Fortaleza: Expressão Gráfica.

. (2012). Objeto de pesquisa em secretariado executivo. In D. G. Durante (org.), Pesquisa em secretariado: cenários, perspectivas e desafios (pp. 119-131). Passo Fundo: Ed. UPF.

Pádua, E. M. M. de (1997). Metodologia da pesquisa: abordagem teórico-prática (4nd ed.). Campinas: Papirus. 
Estado da arte e o rumo do conhecimento científico em secretariado executivo: mapeamento e análise de áreas de pesquisa

Pereira, I. A.; Moreira, N. C. \& Baeta, O. V. (2012). Fatores motivacionais para a pesquisa na área de Secretariado Executivo das IFES brasileiras. Sociais e Humanas, Santa Maria, 25(1), 140155, jan./jun. Retrieved from http://cascavel.ufsm.br/revistas/ojs2.2.2/index.php/sociaisehumanas/article/view/3532

Richardson, R. J. (2008). Pesquisa social: métodos e técnicas (3a ed.). São Paulo: Atlas.

Rodrigues, A. de J. (2006). Metodologia científica. São Paulo: Avercamp.

Sabino, R. F. \& Marchelli, P. S. (2009). O debate teórico-metodológico no campo do secretariado: pluralismos e singularidades. Cadernos EBAPE.BR, 7(4), 607-621, dez. Retrieved from http://www.scielo.br/pdf/cebape/v7n4/06.pdf

Salomon, D. V. (2000). A maravilhosa incerteza: ensaio de metodologia dialética sobre a problematização no processo de pensar, pesquisar e criar. São Paulo: Martins Fontes. 